\title{
Loss of phosphatase activity in myotubularin- related protein 2 is associated with Charcot-Marie-Tooth disease type 4B1
}

\author{
Philipp Berger ${ }^{1}$, Sonja Bonneick ${ }^{1}$, Susan Willi ${ }^{1}$, Matthias Wymann ${ }^{2}$ and Ueli Suter ${ }^{1, *}$ \\ ${ }^{1}$ Institute of Cell Biology, Department of Biology, Swiss Federal Institute of Technology, ETH-Hönggerberg, $\mathrm{CH}-8093$ \\ Zürich, Switzerland and ${ }^{2}$ Institute of Biochemistry, University of Fribourg, $\mathrm{CH}-1700$ Fribourg, Switzerland
}

Received March 13, 2002; Revised and Accepted April 22, 2002

\begin{abstract}
Mutations in the gene encoding myotubularin-related protein 2 (MTMR2) are responsible for autosomal recessive Charcot-Marie-Tooth disease type 4B1 (CMT4B1), a severe hereditary motor and sensory neuropathy characterized by focally folded myelin sheaths and demyelination. MTMR2 belongs to the myotubularin family, which is characterized by the presence of a phosphatase domain. Myotubularin (MTM), the archetype member of this family, is mutated in X-linked myotubular myopathy. Although MTMR2 and MTM are closely related, they are likely to have different functions. Recent studies revealed that MTM dephosphorylates specifically phosphatidylinositol 3-phosphate. Here we analyze the biochemical properties of the mouse Mtmr2 protein, which shares $97 \%$ amino acid identity with human MTMR2. We show that phosphatidylinositol-3-phosphate is also a substrate for Mtmr2, but, unlike myotubularin, Mtmr2 dephosphorylates phosphatidylinositol 3,5-bisphosphate with high efficiency and peak activity at neutral $\mathrm{pH}$. We demonstrate that the known disease-associated MTMR2 mutations lead to dramatically reduced phosphatase activity, suggesting that the MTMR2 phosphatase activity is crucial for the proper function of peripheral nerves in CMT4B1. Expression analysis of Mtmr2 suggests particularly high levels in neurons. Thus, the demyelinating neuropathy CMT4B1 might be triggered by the malfunction of neural membrane recycling, membrane trafficking, and/or endocytic or exocytotic processes, combined with altered axon-Schwann cell interactions. Furthermore, the different biochemical properties of MTM and MTMR2 offer a potential explanation for the different human diseases caused by mutations in their respective genes.
\end{abstract}

\section{INTRODUCTION}

Charcot-Marie-Tooth disease type 4B (CMT4B) is an autosomal recessive demyelinating neuropathy characterized by focally folded myelin sheaths and demyelination of peripheral nerves, associated with reduced nerve conduction velocity. The disease is characterized by onset in early childhood with symmetrical distal and proximal muscle weakness. Adult patients are seriously handicapped and wheelchair-bound (1). Although clinically homogenous, two different gene loci have been identified for CMT4B (2). CMT4B1 was mapped to chromosome 11q22 (3), and myotubularin-related protein 2 (MTMR2) was identified as the disease-causing gene at this locus (4). To date, about half a dozen MTMR2 mutations have been identified $(4,5)$.

MTMR2 belongs to the myotubularin family of eukaryotic phosphatases (6). Myotubularin (MTM), the founder member, was identified by positional cloning to be mutated in X-linked myotubular myopathy (XLMTM) (7). XLMTM is characterized by hypotonia and generalized muscle weakness in newborn males and death within the first months of life. The muscle cells of affected patients show large, centrally located nuclei, which is typical for fetal myotubes, indicating that the muscle is arrested prior to differentiation of myofiber formation (8). Myotubularin-related proteins are defined by the presence of conserved phosphatase and SET (Suvar 3-9, Enhancer of zeste, Trithorax)-interacting domains (SID) $(9,10)$. Although the phosphatase domain was initially identified as a protein tyrosine/dual-specificity phosphatase (PTP/DSP), only minor phosphatase activity towards phosphorylated proteins has been observed in vitro (11). The discovery that phosphatase and tensin homologue (PTEN), a tumor suppressor gene product with a PTP/DSP domain that is frequently mutated in a variety of tumors, dephosphorylates phosphatidylinositol 3,4,5trisphosphate (12) led to the identification of phosphoinositides as the major myotubularin substrates. MTM shows specific activity towards phosphatidylinositol 3-phosphate [PI(3)P], a metabolite that plays a key role in membrane and vesicular 
trafficking in yeast (13) and mammalian cells (14). Phosphoinositides can be further phosphorylated on multiple sites of the inositol ring to generate distinct second messengers that are involved in diverse cellular processes such as cell survival, proliferation, differentiation and cytoskeleton reorganization (15). PI(3)P is constitutively synthesized from phosphatidylinositol by a class III phosphatidylinositol 3-kinase (PI3K) (16) and is specifically located on membranes associated with the endocytic pathway $(17,18)$. PI(3)P recruits proteins with a FYVE zinc-finger domain to these membranes $(19,20)$ and can become phosphorylated by phosphoinositide 5-kinase with a FYVE domain (PIKfyve), an enzyme that localizes to multivesicular bodies, to form phosphatidylinositol 3,5-bisphosphate $\left[\mathrm{PI}(3,5) \mathrm{P}_{2}\right](21)$. This phospolipid is involved in the response to cellular stress (22) and the recycling of membrane from vacuoles/lysosomes (23), and regulates sorting of membrane protein cargo into the vacuole via endosomal multivesicular bodies (24).

To understand the molecular mechanisms underlying the human diseases caused by mutations in the MTM and MTMR2 genes, it is crucial to characterize the biochemical properties of the encoded proteins. In the current study, we show that MTM and Mtmr2 (the mouse orthologue of MTMR2) have distinct biochemical properties. Whereas MTM dephosphorylates mainly PI(3)P (11), Mtmr2 is able to dephosphorylate PI(3)P and $\mathrm{PI}(3,5) \mathrm{P}_{2}$ efficiently. In addition, the two phosphatases exhibit different $\mathrm{pH}$ optima. These results indicate that MTM and Mtmr2 fulfill partially different functions, possibly at different locations within the cell. This is in line with the observation that the two proteins cannot compensate for each other in the disease situation. Mutations in MTMR2 that cause CMT4B1, assayed in the mutated products of the mouse orthologue Mtmr2, lead to drastically reduced enzymatic activity, suggesting a link between the disease and phosphatase activity. CMT4B1 is clinically characterized by demyelination and focally folded myelin sheaths, pointing to a primary defect in the Schwann cell. However, Mtmr2 is highly expressed by motor and sensory neurons, indicating an important contribution of axon-Schwann cell interactions to the disease phenotype (25).

\section{RESULTS}

\section{Sequence of Mtmr2 cDNA}

Mtmr2 cDNA was obtained by RT-PCR from both mouse brain and sciatic nerve RNA and matched the sequences of the available expressed sequence tag (EST) clones. The cDNA codes for a protein of 643 amino acids that shares $97 \%$ identity with the human orthologue (4). Most of the divergent residues are localized towards the $\mathrm{N}$ terminus, whereas the known structural motifs - the GRAM (glucosyltransferase, Rab-like GTPase activator and myotubularin), phosphatase, SID, PDZ (PSD95/Dlg/ZO-1)-binding motifs - are almost completely conserved $(6,10,26,27)$. In addition, the same amino acid residues that are mutated in the characterized CMT4B1 patients are also found in the mouse protein (Fig. 1A). The nearest family members in the mouse, Mtm and Mtmrl, share $63 \%$ and $68 \%$ identity respectively, with Mtmr2 (Fig. 1B).
The genomic structure of the mouse Mtmr2 gene was determined using publicly available genomic sequences and verified by sequencing the exon/intron boundaries on a bacterial artificial chromosome (BAC) clone containing the Mtmr2 gene (S. Bonneick et al., in preparation). The locations of all exon/intron junctions are identical between the human MTMR1 and MTMR2 genes and the mouse Mtmr 2 gene (Fig. 1C, Table 1), except for the untranslated exon 15, which is split into exon 15 and exon 16 in MTMR1 $(4,28)$. We also identified an additional exon between exon 2 and exon 3 by RT-PCR (data not shown) and screening of the EST database (termed exon 2a). Because this exon is only rarely used in mouse (data not shown) and contains two inframe stop codons, the corresponding cDNA was not analyzed further.

\section{Catalytic properties of Mtmr2}

Myotubularins were initially identified as members of the PTP/ DSP family. However, recent studies have shown that phosphoinositides are the main substrates of this family $(11,29)$. Previous experiments revealed that $\mathrm{PI}(3) \mathrm{P}$ is a substrate for MTM $(11,29)$, and $\mathrm{PI}(3,5) \mathrm{P}_{2}$ has been reported to be a substrate for MTMR3 (30). To determine the substrate specificity of Mtmr2, we expressed Mtmr2 protein in Escherichia coli as a fusion protein with N-terminal glutathione $S$-transferase (GST) and C-terminal His(6) tags and measured the phosphatase activity of the resulting fusion protein with different phosphatidylinositol phosphates as substrates in a malachite green-based assay (31). Strong catalytic activity was detected with two of the seven substrates tested. This activity was highest with $\mathrm{PI}(3,5) \mathrm{P}_{2}$, and $\mathrm{PI}(3) \mathrm{P}$ was dephosphorylated at an approximately 4-fold lower rate (Fig. 2A). Mtmr2 showed only minimal dephosphorylation of PI(4)P, PI(5)P, PI $(3,4) \mathrm{P}_{2}$, $\mathrm{PI}(4,5) \mathrm{P}_{2}$ and $\mathrm{PI}(3,4,5) \mathrm{P}_{3}$. To identify which phosphate group was released by $\mathrm{Mtmr} 2$ from $\mathrm{PI}(3,5) \mathrm{P}_{2}$, two different assays were carried out. Using substrates fluorescently labeled on the fatty acid chain, we show that $\mathrm{PI}(3,5) \mathrm{P}_{2}$ is converted to $\mathrm{PI}(5) \mathrm{P}$ and not to phosphatidylinositol, demonstrating that only a single phosphate was removed. In the same assay, Mtmr2 dephosphorylated PI(3)P to phosphatidylinositol, but PI(5)P was not dephosphorylated (Fig. 2B). When phosphatidylinositol, $\mathrm{PI}(4) \mathrm{P}$ and $\mathrm{PI}(5) \mathrm{P}$ were radioactively labeled at position D3 with PI3K, Mtmr2 was able to remove the radioactivity from $\mathrm{PI}(3) \mathrm{P}$ and $\mathrm{PI}(3,5) \mathrm{P}_{2}$, indicating that the phosphate at position D3 is removed (Fig. 2C). $\mathrm{PI}(3,5) \mathrm{P}_{2}$ was not completely dephosphorylated at D3 in this assay, although it was incubated with an excess of enzyme - possibly because the specific conditions in the PI3K-coupled assay were not optimal. $\mathrm{PI}(3,4) \mathrm{P}_{2}$ was not a substrate, confirming the results from the malachite green-based assay. We conclude that $\mathrm{PI}(3) \mathrm{P}$ and, in particular, $\mathrm{PI}(3,5) \mathrm{P}_{2}$ are the main substrates for $\mathrm{Mtmr} 2$, which selectively removes the phosphate at position D3, but not at position D5.

We also determined the influence of the $\mathrm{pH}$ on the catalytic activity of Mtmr2 to obtain some indirect insights about its subcellular localization. The phosphatase activity was highest between $\mathrm{pH} 7.0$ and 7.5, and was strongly reduced at $\mathrm{pH} 6.5$ and below. These results did not depend on the substrate, since $\mathrm{PI}(3) \mathrm{P}$ and $\mathrm{PI}(3,5) \mathrm{P}_{2}$ showed the same $\mathrm{pH}$ dependence (Fig. 3). 
A

MTMR2

METSSSCESL GSQPAAARPP SVDSLSSAST SHSENSVHTK SASVVSSDSI STSADNFSPD

Mtmr2

MEKSSSCESL GAQLPAARLP SEDSLSSAST SHSENSVHTK SASAISSDSI STSADNFSPD

MTMR2 LRVLRESNKL AEMEEPPLLP GENIKDMAKD VTYICPFTGA VRGTLTVTNY RLYFKSMERD

Mtmr2

LRVLREANKL AEMEEPALLP

GRAM

MTMR2

PPFVLDASLG VINRVEKIGG

180

Mtmr2

PPFVLDASLG VISRVEKIGG

LETVCKDIRN LRFAHKPEGR TRRSIFENLM

MTMR2

Mtmr2

KYAFPVSNNL PLFAFEYKEV FPENGWKLYD PLLEYRRQGI PNESWRITKI NERYELCDTY

KYAFPVSNGL PLFAFEYKEV FPENGWKLYD PLLEYRRQGI PNESWRITKI NERYELCDTY

MTMR2

PALLVVPANI PDEELKRVAS FRSRGRIPVL SWIHPRSOAT ITRCSOPMVG VSGKRSKEDE

Mtmr2

PALLVVPANI PDEELKRVAS FRS

Phosphatase

300

MTMR2

Mtmr2

KYLQAIMDSN AQSHKIFIFD ARPSVNAVAN KAKGGGYESE DAYQNAELVF LDIHNIHVMR KYLQAIMDSN AQSHKIFIFD ARPSVSAVAN KAKGGGYESE DAYQNAELVF LDIHNIHVMR

MTMR2

ESLRKLKEIV YPNIEETHWL SNLESTHWLE HIKLILAGAL RIADKVESGK TSVVVHCSDG

Mtmr2

ESLRKLKEIV YPTIEETHWL SNLESTHWLE HIKLILAGAL RIADKVESGK TSVVVHCSDG

480

MTMR2

Mtmr2

WDRTADLTSL AMLMLDGYYR TIRGFEVLVE KEWLSFGHRF QLRVGHGDKN HADADRSPVF WDRTAQETSL AMLMLDGYYR TIRGFEVLVE KEWLSFGHRF QLRVGHGDKS HADADRSPVF

MTMR2

作

Mtmr2 I FIDCVWQM TRQEPTAFEF NEYFLITILD HLYSCLFGTF LCNSEQQRGK ENLPKKTVSL SID

MTMR2 WSYINSQLED FTNPLYGSYS NHVLYPVASM RHLELWVGYY IRWNPRMKPQ EPIHNRYKEL

Mtmr2 WSYINSQLED FTNPLYGSYS NHVLYPVASM RHLELWVGYY IRWNPRMKPQ EPIHSRYKEL

MTMR2 LAKRAELQKK VEELQREISN RSTSSSERAS SPAQCVTPVQ TVV

Mtmr2 LAKRAELQRK VEELQREISN RSTSSSERAS SPAQCVTPVQ TVV PDZ-binding

B

\begin{tabular}{|l|c|c|c|c|c|c|}
\hline & MTM & MTMR1 & MTMR2 & Mtm & Mtmr1 & Mtmr2 \\
\hline MTM & $\mathrm{x}$ & & & & & \\
\hline MTMR1 & 59 & $\mathrm{x}$ & & & & \\
\hline MTMR2 & 65 & 69 & $\mathrm{x}$ & & & \\
\hline Mtm & 92 & 58 & 64 & $\mathrm{x}$ & & \\
\hline Mtmr1 & 59 & 93 & 69 & 58 & $\mathrm{x}$ & \\
\hline Mtmr2 & 64 & 68 & 97 & 63 & 68 & $\mathrm{x}$ \\
\hline
\end{tabular}

C

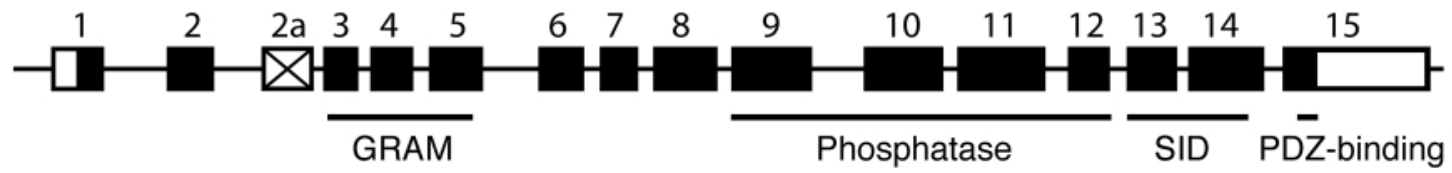

Figure 1. Characterization of the Mtmr2 gene. (A) Alignment of the mouse Mtmr2 amino acid sequence with the corresponding human MTMR2 sequence. Differences are marked in bold, known mutations in human patients are boxed and the characterized structural motifs are shaded. (B) Degree of amino acid identity within the myotubularin family given in percentages. (C) Genomic organization of the mouse Mtmr 2 gene. Exon $2 \mathrm{a}$ is an alternatively spliced exon containing two stop codons. Black boxes are translated regions and white boxes are untranslated regions. Intron sizes are not drawn to scale. 
Table 1. Exon/intron organization of the Mtmr2 gene

\begin{tabular}{|c|c|c|c|c|}
\hline \multicolumn{2}{|l|}{ Acceptor site } & $\begin{array}{l}\text { Exon number (size) } \\
\text { Exon } 1 \text { (>120 bp) }\end{array}$ & \multicolumn{2}{|l|}{ Donor site } \\
\hline ttgtcttttgtag & TGCTTCTACT & Exon $2(106 \mathrm{bp})$ & TGACTTGAGG & gtatgtatattgc \\
\hline aatccetcacag & GAGTGCCCAG & Exon $2 \mathrm{a}(105 \mathrm{bp})$ & AATTCTATAG & gtaagtcacataa \\
\hline tttgtcgtttcag & CCAAAGATGT & Exon 4 (95 bp) & CATGGAGCGG & gtgaggcttcttg \\
\hline tttcatcttgcag & GACCCCCCAT & Exon 5 (111 bp) & TGTGTGCAAG & gtaaattttacaa \\
\hline atatcttttctag & GATATCAGGA & Exon 6 (102 bp) & TAATGGCTTG & gtaaatgtttctc \\
\hline ccetcttttgcag & GCAAAGGGGG & Exon 10 (186bp) & ACACATTAAG & gtgtgtatttact \\
\hline aacttgttttcag & CTCATTCTTG & Exon 11 (207 bp) & АTTCCAACTA & gtgagtaaagaac \\
\hline gtctttgcttcag & AGAGTTGGCC & Exon $12(93 \mathrm{bp})$ & GACAAGACAG & gtaagacgtcatc \\
\hline gctcaatttgcag & TTCCСТACCG & Exon 13 (114bp) & GGGGAAAGAG & gtaaagtatgatc \\
\hline ttccetcttgcag & AATCTTCCTA & Exon 14 (177bp) & GAAACCTCAG & gtacatatctgta \\
\hline tttgctcttgcag & GAACCTATCC & Exon 15 (>1050 bp) & & \\
\hline
\end{tabular}

\section{Influence of CMT4B1-associated mutations on the function of MTMR2}

To understand the molecular basis of CMT4B1, we studied the effects of disease-associated mutations on phosphatase activity. MTM mutations have been shown to result in loss of catalytic activity, but the tested mutations were all localized in or nearby the phosphatase domain (11). Three described MTMR2 mutations directly affect the phosphatase domain (E276X, Q426X and Q482X), and it might have been anticipated that they have lost their catalytic activities (Fig. 4A). Interestingly, the CMT4B1-associated deletion of amino acids phenylalanine 494 to glutamate 531, which corresponds to a skipping of exon 13 (coding for part of the SID domain adjacent to the phosphatase domain; Fig. 1A), as well as a stop mutation at tyrosine 579, also led to a complete loss of phosphatase activity. Only the missense mutation G103E, which is located approximately 150 amino acids $\mathrm{N}$-terminal to the phosphatase domain, retained marginal catalytic activity (Fig. 4A). Loss of catalytic activity was observed with both substrates, $\mathrm{PI}(3,5) \mathrm{P}_{2}$ and PI(3)P, on all mutants mentioned above. This effect appears to be specific for the disease-associated forms, because other, artificially designed, Mtmr2 mutations in the phosphatase domain (K333T and R443E) or the deletion of the PDZbinding motif (T641X) did not cause loss of phosphatase activity (data not shown).

\section{Expression of MTMR2 in the nervous system}

Since mutations in the human MTMR2 gene lead to the demyelinating disease CMT4B1, we analyzed the expression of this phosphatase in the peripheral nervous system (PNS) of the mouse. In situ hybridization with an Mtmr2 antisense probe revealed a strong signal in dorsal root ganglia (DRG) (Fig. 5A) and in motor neurons (Fig. 6F). No signal was obtained with the corresponding Mtmr2 sense probe (Fig. 5B). Surprisingly, no discernible staining was observed in the peripheral nerve, possibly because of limited sensitivity of the assay, since RTPCR analyses of sciatic nerve tissue revealed detectable Mtmr2 mRNA (data not shown). To examine whether the strong staining observed by in situ hybridization analysis of DRG was due to neuronal or glial Mtmr2 expression, we performed double immunostainings on dissociated DRG cultures with anti-Mtmr2 antibodies and the glial marker Sox10 (32) (Fig. 5C). Sensory neurons (as judged by morphology in Fig. 5C and double staining with anti-neurofilament antibodies; data not shown) display high expression of Mtmr2 mainly in the cell soma and neurites. In contrast, Mtmr2 immunoreactivity was not detected in Sox10-positive satellite glial cells (Fig. 5C). Neuronal expression of Mtmr2 was also found in the central nervous system (CNS) (Fig. 6). Mtmr2 transcripts were detected in the mitral cells of the olfactory bulbs (Fig. 6A), in distinct thalamic nuclei and in nuclei of the globus pallidus (Fig. 6B), in all CA fields of the hippocampus and in the dentate gyrus (Fig. 6C), in Purkinje cells of the cerebellum (Fig. 6D), and in the deep cerebellar nuclei (Fig. 6E). In the pons, expression was found in the vestibular nuclei, the spinal trigeminal nuclei and the facial nuclei (Fig. 6E).

Since ubiquitous expression of MTMR2 has been reported based on northern blot analysis of human tissue (6) and because of the early onset of CMT4B1, we examined Mtmr2 expression in mouse embryos. Widespread expression was observed at embryonal day 16.5 , with particularly high levels in the forebrain, DRG, the facial and trigeminal ganglia, kidney, adrenal gland, and lung (Fig. 7).

\section{DISCUSSION}

Mutations in the human MTMR2 gene are responsible for CMT4B1, a severe autosomal recessive peripheral neuropathy. MTMR2 is highly conserved in many species and there are at least eight related proteins in human and mice (6). Interestingly, mutations in one of the closest MTMR2 homologues, MTM, cause the severe disorder X-linked myotubular myopathy. Hence, although these proteins are highly similar and have in part overlapping expression patterns (6), they are not completely redundant. In order to understand the molecular basis of these distinct effects, we have analysed the enzymatic properties of Mtmr2 and 
A

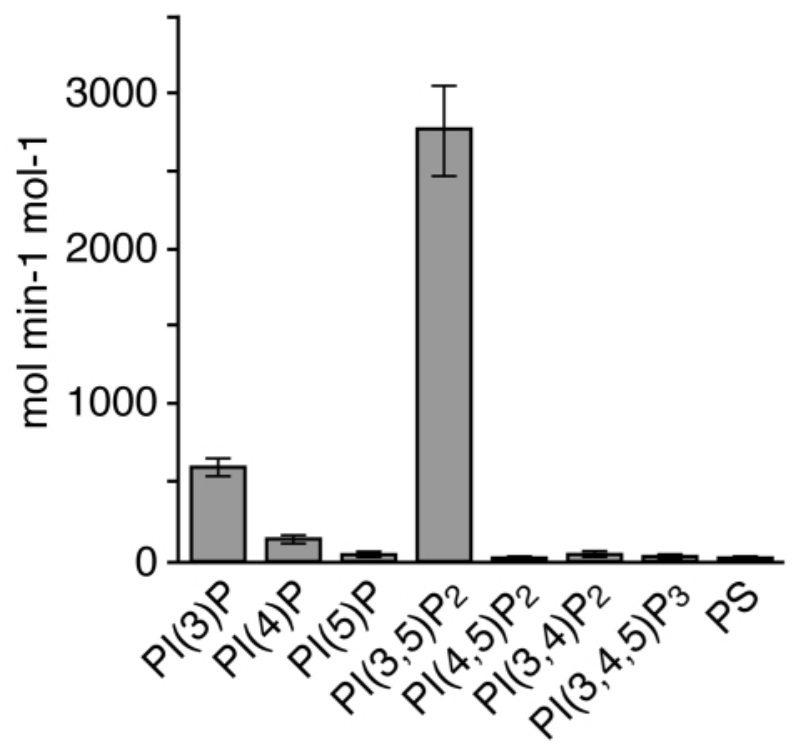

B

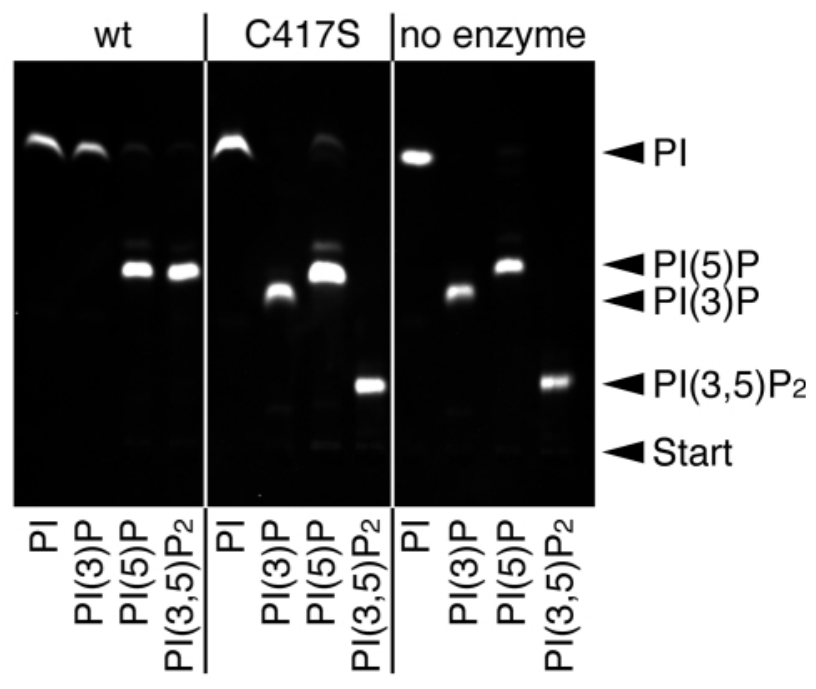

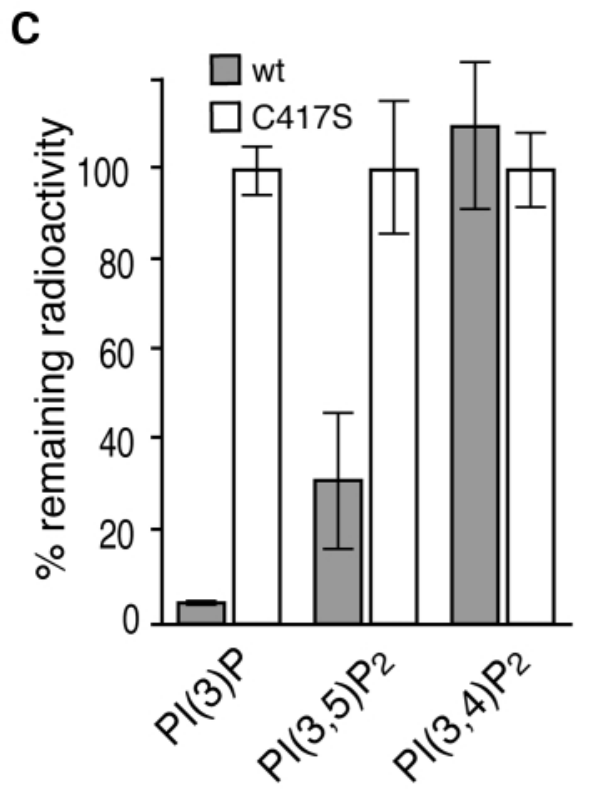

Figure 2. Substrate specificity of Mtmr2. (A) Mtmr2 dephosphorylates mainly $\mathrm{PI}(3,5) \mathrm{P}_{2}$ and $\mathrm{PI}(3) \mathrm{P}$ in a malachite green-based assay. The other five substrates tested were dephosphorylated with much reduced activity. The lipid carrier in this reaction, phosphatidylserine (PS), was tested separately as a negative control. Enzyme-specific activity is expressed as moles of phosphate released per minute per mole of enzyme (mean \pm SD, $n=3$ ). (B) Di-C6-NBD6-phosphoinositide substrates were incubated with wild-type Mtmr2, mutant Mtmr2 C417S (inactivated phosphatase domain) and without enzyme. Wild-type Mtmr2 dephosphorylated $\mathrm{PI}(3,5) \mathrm{P}_{2}$ to $\mathrm{PI}(5) \mathrm{P}$ and $\mathrm{PI}(3) \mathrm{P}$ to phosphatidylinositol (PI). (C) Dephosphorylation of substrates labeled with $\left[{ }^{32} \mathrm{P}\right]$ phosphate at position $\mathrm{D} 3$. $\mathrm{PI}(3,5) \mathrm{P}_{2}$ and $\mathrm{PI}(3) \mathrm{P}$ lose radioactivity after treatment with an excess of Mtmr2, indicating that Mtmr2 acts at position D3. PI(3,4) $\mathrm{P}_{2}$ was not dephosphorylated; see also $(\mathrm{A})$.

compared them with the available data on other proteins of the myotubularin family.

Recombinant Mtmr2 was expressed in E. coli as a fusion protein and its phosphatase activity towards different phosphoinositides was measured. Mtmr2 dephosphorylates $\mathrm{PI}(3,5) \mathrm{P}_{2}$ and $\mathrm{PI}(3) \mathrm{P}$ with high efficiency and shows only marginal activity towards the other substrates tested. Kim et al. (33) showed also in a very recent report that MTMR2 is able to dephosphorylate $\mathrm{PI}(3) \mathrm{P}$, but did not detect activity towards
$\mathrm{PI}(3,5) \mathrm{P}_{2}$. We have tested $\mathrm{PI}(3,5) \mathrm{P}_{2}$ from two different suppliers in the malachite green-based assay and have reproducibly observed $\mathrm{PI}(3,5) \mathrm{P}_{2}$ dephosphorylation. Equal substrate specificity was observed when substrates containing a fluorescent label on the fatty acid chain were used and with substrates that were labelled enzymatically to incorporate $\left[{ }^{32} \mathrm{P}\right]$ phosphate at the $\mathrm{D} 3$ position of phosphoinositides using recombinant $\mathrm{PI} 3 \mathrm{~K} \gamma$. Based on these data, we conclude that Mtmr2 dephosphorylates also $\mathrm{PI}(3,5) \mathrm{P}_{2}$ at its $\mathrm{D} 3$ position to produce $\mathrm{PI}(5) \mathrm{P}$. 


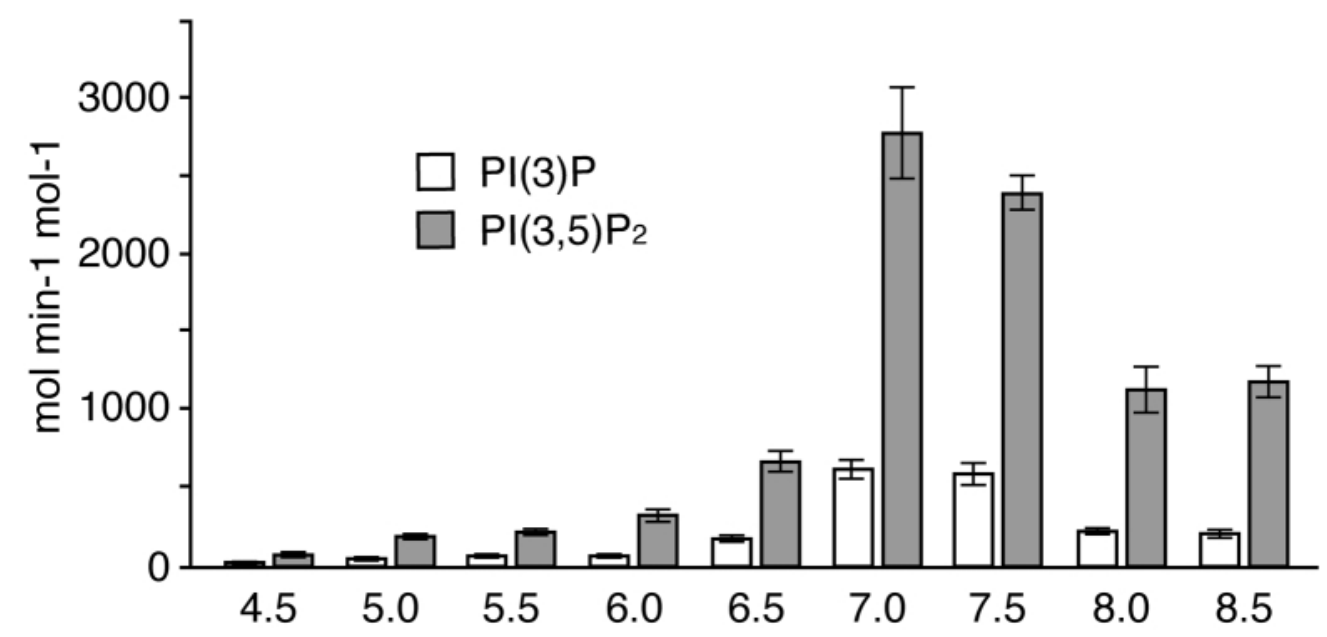

Figure 3. $\mathrm{pH}$ dependence of the catalytic activity. The $\mathrm{pH}$ dependence of the phosphatase activity was measured using a malachite green-based assay. The activity peaked between $\mathrm{pH} 7.0$ and 7.5 and was independent of the substrate used. Enzyme specific activity is expressed as moles of phosphate released per minute per mole of enzyme (mean $\pm \mathrm{SD}, n=3$ ).

While several studies describe the important and established function of $\mathrm{PI}(3) \mathrm{P}$ in endocytosis and vesicular trafficking $(17,18)$, less is known about the functions of $\mathrm{PI}(3,5) \mathrm{P}_{2}$. The basal level of this lipid is low compared with those of other phosphatidylinositol phosphates, especially PI(3)P (22). $\mathrm{PI}(3,5) \mathrm{P}_{2}$ levels are, however, transiently increased by external signals such as hypoosmotic stress (22) or treatment with ultraviolet light (34). Also, more physiological signals, such as the stimulation of B and T cells with interleukin-2, lead to an increase in $\mathrm{PI}(3,5) \mathrm{P}_{2}(34)$. Functional approaches in mammalian cells by blocking $\mathrm{PI}(3,5) \mathrm{P}_{2}$ production using overexpression of a kinase-inactive form of PIKfyve caused swollen vacuoles, indicating that $\mathrm{PI}(3,5) \mathrm{P}_{2}$ is important for cell morphology and membrane homeostasis (35). Similarly, inactivation of the yeast PIKfyve orthologue Fablp leads to vacuolar acidification and increased vacuole size (23). These and other studies show conclusively that correct regulation of $\mathrm{PI}(3,5) \mathrm{P}_{2}$ levels is crucial for cell morphology, vesicular trafficking and membrane homeostasis. The function of the accumulated PI(5)P remains to be elucidated, but recent studies suggest that it is also involved in the cellular stress response in plants (36).

MTMR2 is not the only protein of the myotubularin family that shows this substrate specificity. MTMR3/FYVE-DSP1 also dephosphorylates $\mathrm{PI}(3,5) \mathrm{P} 2$ and $\mathrm{PI}(3) \mathrm{P}$, but its maximal activity is at $\mathrm{pH} 4.5(30,37)$. MTMR3 together with MTMR4/FYVEDSP2 forms a subgroup in the myotubularin gene family with a different domain composition. These enzymes contain a C-terminal FYVE domain, indicating that they are targeted to $\mathrm{PI}(3) \mathrm{P}$-containing membranes. The precise subcellular localization of MTMR2 is not yet known, but it is likely that it acts in the cytosol or in non-acidic vesicles, based on its optimal

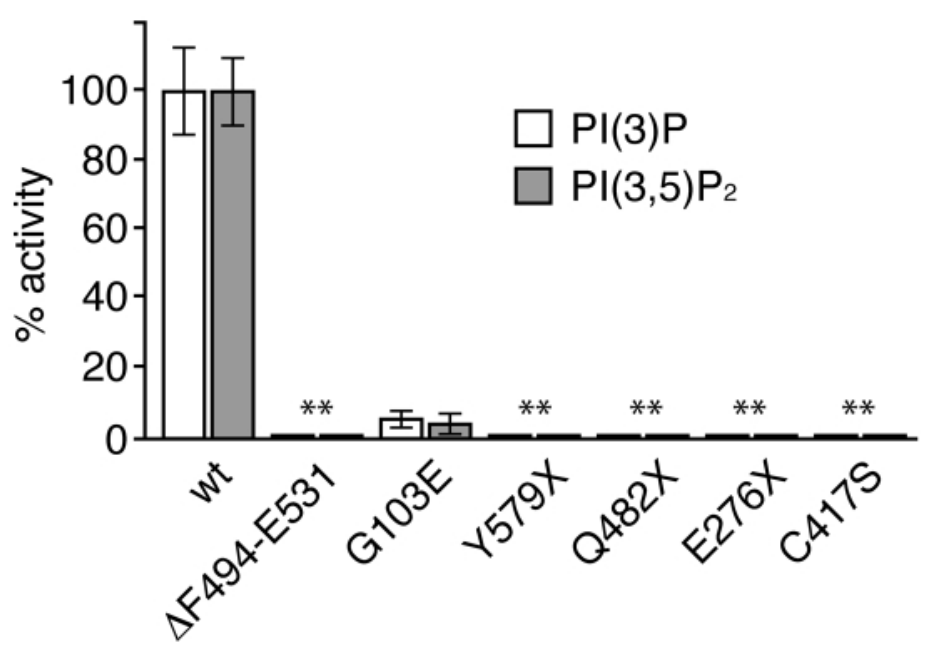

Figure 4. Enzymatic activities of disease-associated forms. Four of the five disease-associated Mtmr2 proteins tested lose their catalytic activity completely; only G103E retains some residual activity (the disease-associated frameshift mutation at Y579 was mimicked by a stop mutation). C417S is a negative control with a mutation of the cysteine in the active site (mean $\pm \mathrm{SD} ; n=3 ; * *$, below detection limit). 

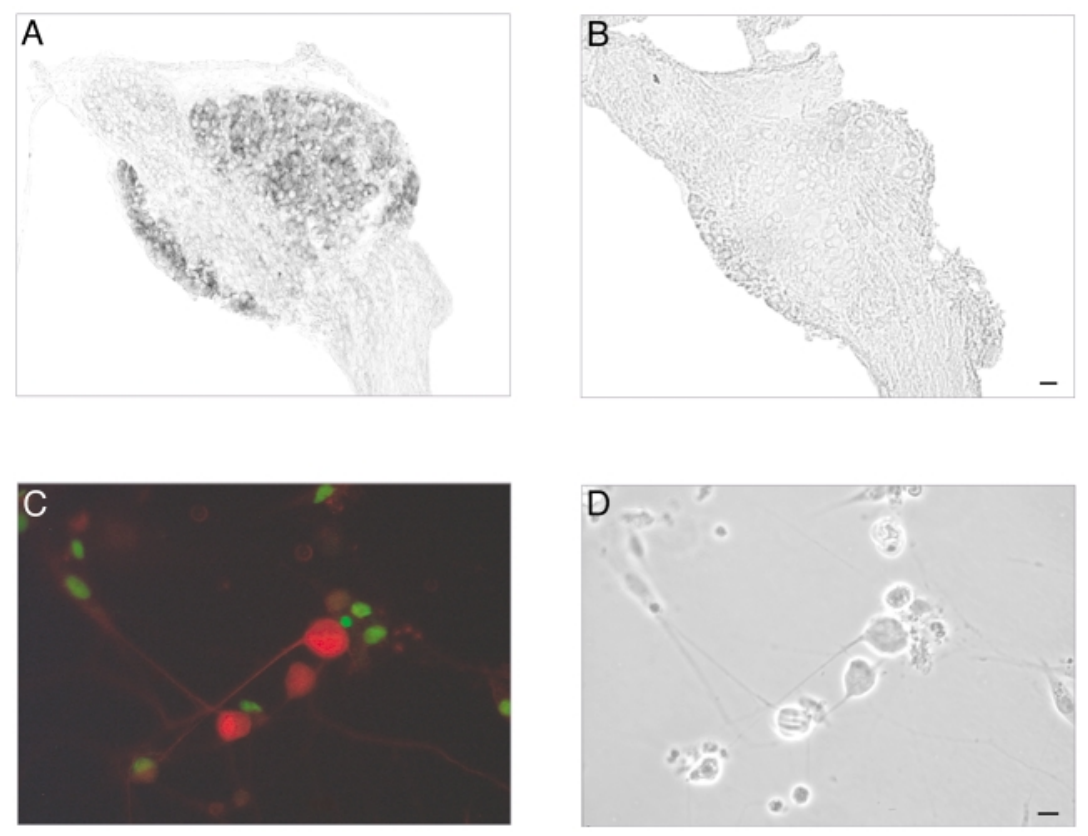

Figure 5. Expression of Mtmr2 in the murine DRG and sciatic nerve. (A) Mtmr2 expression revealed by in situ hybridization in the DRG of mice at postnatal day 6 . (B) Hybridization with the sense probe showed no signal. (C) Immunostaining of dissociated DRG cultures. Morphologically identifiable neurons were Mtmr2 positive. The Mtmr2 (red) staining does not co-localize with the glial marker Sox10 (green). (D) Phase picture. Bar in (B) for (A) and (B) equals $50 \mu \mathrm{m}$; bar in (D) for (C) and (D) equals $20 \mu \mathrm{m}$.

activity at neutral $\mathrm{pH}$. Indeed, recent results suggest a cytosolic and membrane-associated localization of MTMR2 as well as an ability to relocalize to rac-induced membrane ruffles (38).

Our analysis of CMT4B1-associated MTMR2 mutations revealed that four of five mutated proteins tested lost their phosphatase activity completely, and one mutant (Mtmr2 G103E) retained only very low catalytic activity. Although we cannot exclude other contributing factors, including altered protein stability and/or mislocalization of the mutant proteins, these results indicate that CMT4B1 is strongly correlated with the loss of MTMR2 phosphatase activity, as described previously for MTM in X-linked myotubular myopathy (11). Based on our data and the function of the substrates and products of MTMR2 mentioned above, a defect in membrane homeostasis and vesicular transport of lipids and/or proteins related to altered phosphatidylinositol metabolism and potentially cellular stress might be the crucial element in the molecular basis of CMT4B1. Such a disease mechanism would be in line with the special metabolic requirements of Schwann cells, in that they might be particularly vulnerable to such imbalances during myelination, when huge amounts of lipids and proteins have to be synthesized and accurately trafficked within a short period of time. The deleterious problem could be either due to a more systemic effect, or altered trafficking of specific myelin components might cause CMT4B1 indirectly. In agreement with such a hypothesis, CMT4B1 has been clinically classified as a demyelinating neuropathy. To date, all forms of demyelinating neuropathies have been associated with genetic defects leading to aberrant Schwann cell function (recently reviewed in 25). Interestingly and surprisingly, our expression analysis suggests that Mtmr2 is mainly expressed in the adult by neurons. In the PNS, we observed strong expression in the DRG, while no signal was detectable in Schwann cells. To confirm this result, we examined the Mtmr2 mRNA level in the DRG in comparison to the sciatic nerve by quantitative RT-PCR. Indeed, higher levels were found in the DRG (data not shown). Nevertheless, low levels of Mtmr2 mRNA were also present in the adult sciatic nerve, and this expression may be important for the formation and stability of the myelin sheath. However, given the intimate communication between Schwann cells and neurons in peripheral nerves, a primary neuronal phenotype, possibly due to defects in neuronal vesicle trafficking and/or endocytosis, is not inconceivable, followed by secondary demyelination (25). Alternatively, the CMT4B1 disease mechanism might involve both neurons and glial cells. Tissue-specific gene ablation techniques will be required to determine the contributions of the individual cell types.

Mtmr2 expression is not restricted to the PNS, since we observed neuronal expression in various areas of the CNS. Interestingly, CMT4B1 patients do not show a CNS phenotype, although the pronounced cranial nerve involvement in the disease might be related to the strong expression of Mtmr2 in brain stem nuclei.

In summary, we provide evidence that MTMR2 and MTM have distinct biochemical properties that may help to explain the different human diseases associated with mutated forms of these proteins and the lack of redundancy despite overlapping expression patterns. Additional factors may also contribute, including other substrates yet to be discovered, or other domains 

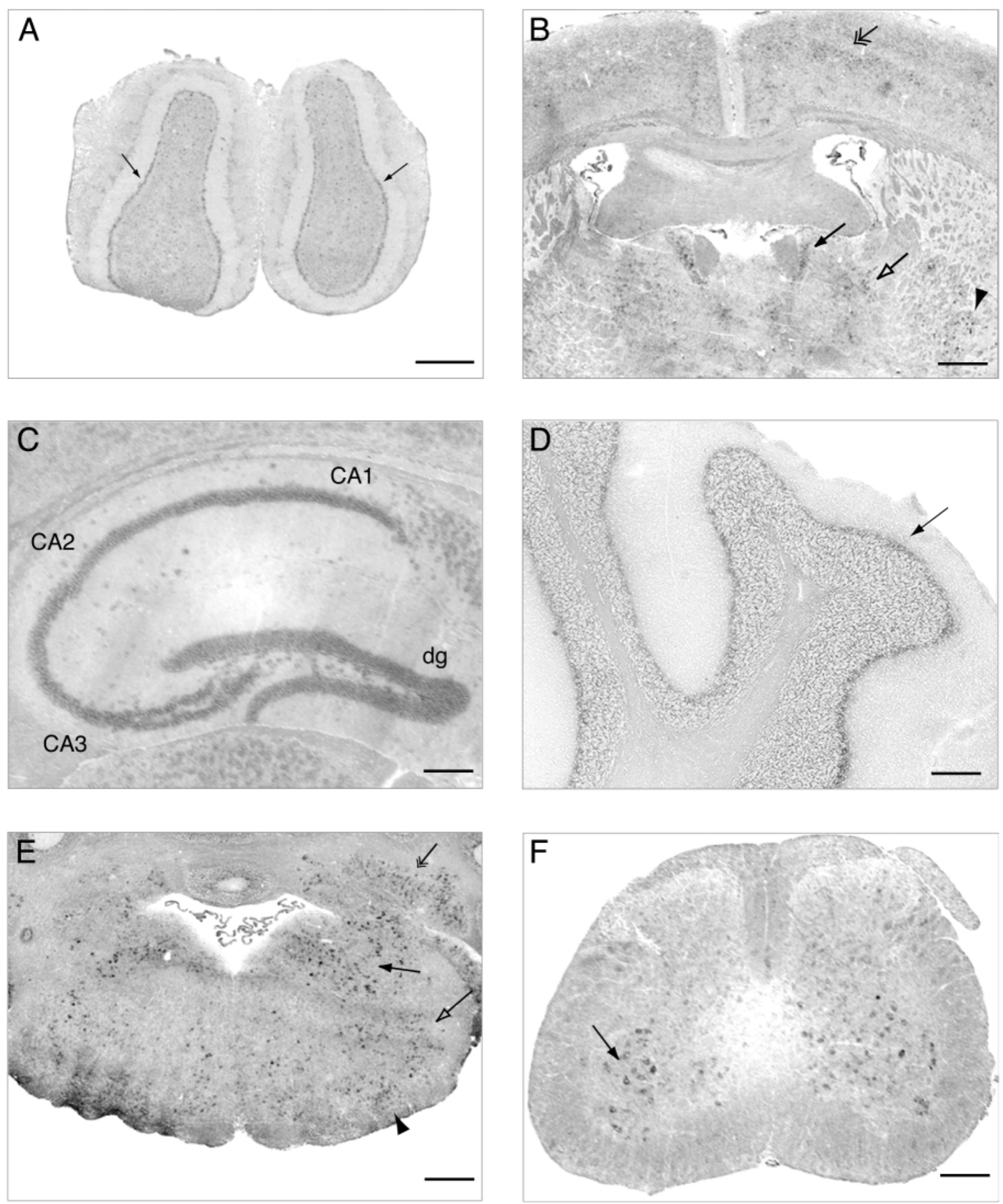

Figure 6. Expression of Mtmr2 in the adult mouse CNS. Expression was found in (A) the mitral cell layer (arrow) of the olfactory bulbs, (B) the cerebral cortex (double arrow), the anteriodorsal (arrow) and reticular (open arrow) thalamic nuclei, as well as nuclei of the globus pallidus (arrowhead), (C) the CA1, CA2 and CA3 regions of the hippocampus and the dentate gyrus (dg), (D) the Purkinje cells (arrow), and (E) the lateral nuclei of the cerebellum (double arrow), the vestibular nuclei (arrow), the spinal trigeminal nuclei (open arrow) and the facial nuclei (arrowhead) of the pons. (F) Expression in the spinal cord is detected mainly in the ventral horn in morphologically identifiable motorneurons (arrow). Bars in (A)-(C) and (E) are $500 \mu \mathrm{m}$; bar in (D) is $100 \mu \mathrm{m}$, and bar in (F) is $250 \mu \mathrm{m}$.

of these proteins that might be necessary to give the proteins a restricted subcellular localization thereby restricting them to specific functions. A detailed analysis of the members of this intriguing family of phosphatases, including determining their cellular expression levels, precise subcellular localization, and the identification of potentially associated proteins in different physiological conditions of neurons and glial cells, will be required to elucidate the molecular basis of CMT4B1. 


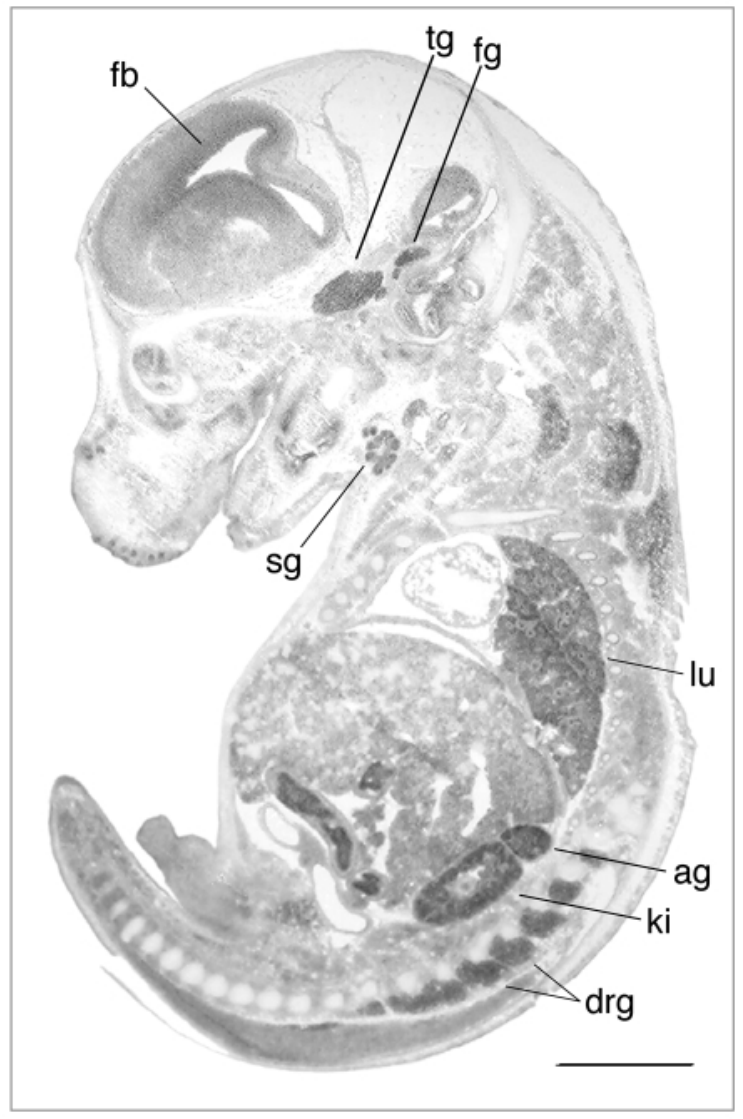

Figure 7. In situ hybridization on a sagital section of an E16.5 mouse embryo. $\mathrm{Mtmr} 2$ expression is prominent in the forebrain ( $\mathrm{fb}$ ), trigeminal ganglion ( $\mathrm{tg}$ ), facial ganglion (fg), submandibular gland (sg), lung (lu), adrenal gland (ag), kidney (ki) and dorsal root ganglia (drg). Bar equals $1 \mathrm{~mm}$.

\section{MATERIALS AND METHODS}

\section{Isolation of mouse Mtmr2 cDNA}

The Mtmr2 cDNA was obtained by RT-PCR using RNA from adult mouse brain and sciatic nerve as template. Three different, overlapping fragments were generated with primers based on known EST sequences. Fragment 1 containing the first $678 \mathrm{bp}$ of the coding region was amplified with the primers MTMR2-for1 (5'-GCA KCG GCC TCC AGT TTC TC-3') and pho-back (5'-TGC CTT CTG TAC TCT AGA AGG-3'), fragment 2 containing the following $940 \mathrm{bp}$ with the primers pho2-for ( $5^{\prime}$-AAT GGG TGG AAA CTG TAT GAC C-3') and pho5-back (5'-ATA ACC AGC TGT ACA AGT GGT CC-3'), and fragment 3 with the remaining $478 \mathrm{bp}$ of the coding region and 887 bp of the $3^{\prime}$-untranslated region with the primers pho4for (5'-GGC AAA TGA CAA GAC AGT TCC-3') and pho6back (5'-TTG TTA CAG TAC ATT ACA TAT GG-3'). For each fragment, two clones from independent RT-PCR reactions were sequenced. The full-length Mtmr2 cDNA was then obtained by fusing these fragments using the BamHI site on fragments 1 and 2 and the EcoRI site on fragments 2 and 3 .

\section{Constructs for expression in $E$. coli}

Recombinant Mtmr2 protein for biochemical analysis was produced in $E$. coli as a fusion protein with N-terminal glutathione $S$-transferase (GST) and C-terminal His(6) tags. A BamHI site adjacent to the start ATG of the Mtmr2 cDNA and the C-terminal His(6) tag with an EcoRI site were introduced with a PCR-based strategy using the primers GST-MTMR2-for (5'-CGT AGT GGA TCC ATG GAG AAG AGC TCC AGC TG-3') and MTMR2-Hisback (5'-AAC AAC GAA TTC TCA ATG GTG ATG GTG ATG GTG TAC AAC AGT TTG GAC$\left.3^{\prime}\right)$. The resulting cDNA was cloned into the BamHI/EcoRI-cut pGEX-2T vector (Pharmacia). The resulting vector pGEXMtmr2 was used for the expression of wild-type protein and as the starting point for the expression constructs of the mutated forms of Mtmr2. The following primers were used for mutagenesis: E276X (5'-GAT CGA ATT CTC AGT GAT GGT GAT GGT GAT GAA GAT GAA TCC AGG A-3'), Q426X (5'-GAT CGA ATT CTC AGT GAT GGT GAT GGT GAT GAG CTG TGC GAT CCC A-3'), Q482X (5'-GAT CGA ATT CTC AGT GAT GGT GAT GGT GAT GAA GGA AAA CAG GTG A-3'), Y579X (5'-GAT CGA ATT CTC AGT GAT GGT GAT GGT GAT GTC CCA CCC AGA GCT C-3'), DelEx13a (5'-ATT GAC TGT GTC TGG CAA ATG ACA AGA CAG AAT CTT CCT AAG AAG-3'), DelEx13b (5'-GAC AGG TCA CCT GTT TTC CTT CAG TTT ATT GAC TGT GTC TGG-3'), G103E (5'-GAC TTA CAT ATG TCC ATT CAC TGG TGC TGT GCG AGA AAC GCT GAC TGT C-3'), PDZ-Del (5'-GAT CGA ATT CTC AGT GAT GGT GAT GGT GAT GTT GGA CAG GAG TCA C-3') and C417S (5'-GGG AAG ACG TCT GTG GTG GTA CAC TCC AGT GAT GGA TGG-3').

\section{Protein expression and purification}

For protein expression, 11 of LB/ampicillin medium was inoculated with a $50 \mathrm{ml}$ overnight culture of E. coli BL21 (DE3) cells (Stratagene) transformed with the pGEX-Mtmr2 expression plasmids constructed as described above. The bacteria were shaken for $4 \mathrm{~h}$ at room temperature, induced with $0.8 \mathrm{~mm}$ isopropyl- $\beta$-D-thiogalactopyranoside (IPTG), and then further incubated for $16 \mathrm{~h}$ at room temperature. After centrifugation, the cells were lysed by sonification in lysis buffer $(20 \mathrm{~mm}$ Tris- $\mathrm{HCl}, 300 \mathrm{~mm} \mathrm{NaCl}, 10 \mathrm{~mm}$ imidazole, $1 \%$ Triton X-100, $20 \mathrm{~mm} \beta$-mercaptoethanol and $1 \mathrm{~mm}$ PMSF, $\mathrm{pH}$ 8.0). The lysate was then centrifuged for $30 \mathrm{~min}$ at 13000 r.p.m. in a SS34 rotor, and supernatant containing the soluble protein was loaded on Ni-NTA agarose beads (Qiagen). The beads were washed twice with washing buffer $(20 \mathrm{~mm}$ Tris- $\mathrm{HCl}, 300 \mathrm{~mm} \mathrm{NaCl}$ and $20 \mathrm{~mm}$ imidazole, $\mathrm{pH} 8.0)$ and then eluted with elution buffer $(20 \mathrm{~mm}$ Tris- $\mathrm{HCl}, 300 \mathrm{~mm} \mathrm{NaCl}$ and $250 \mathrm{~mm}$ imidazole, $\mathrm{pH} 8.0$ ). The eluate was loaded on GSTSepharose (Pharmacia), washed once with washing buffer, and then eluted with $10 \mathrm{~mm}$ reduced glutathione in $50 \mathrm{~mm}$ Tris $-\mathrm{HCl}$ ( $\mathrm{pH}$ 8.0). The concentration of the protein was determined by SDS-PAGE with bovine serum albumin (BSA) as standard. Glycerol was added to a final concentration of $30 \%$, and the protein was stored at $-20^{\circ} \mathrm{C}$. 


\section{Phosphoinositide phosphatase assay}

Phosphoinositides were obtained from the following sources: $\mathrm{PI}(3) \mathrm{P}, \mathrm{PI}(4) \mathrm{P}, \mathrm{PI}(4,5) \mathrm{P}_{2}, \mathrm{PI}(3,4) \mathrm{P}_{2}$ and $\mathrm{PI}(3,4,5) \mathrm{P}_{3}$ from Calbiochem, $\mathrm{PI}(5) \mathrm{P}$ from Echelon, and $\mathrm{PI}(3,5) \mathrm{P}_{2}$ from Calbiochem and Echelon. The lipids were dissolved in chloroform/methanol/water $(50: 50: 15 \mathrm{v} / \mathrm{v})$ and the appropriate amounts were deposited in a $1.5 \mathrm{ml}$ reaction tube. The organic solvent was removed under reduced pressure before the aqueous reaction buffer was added, and a lipid suspension was formed by sonication. Assays were performed at $37^{\circ} \mathrm{C}$ in a buffer consisting of $50 \mathrm{~mm}$ sodium acetate, $25 \mathrm{~mm}$ BisTris, $25 \mathrm{~mm}$ Tris, $2 \mathrm{~mm}$ DTT, $5 \%$ glycerol, $50 \mu \mathrm{m}$ phosphoinositide phosphate and $0.5 \mathrm{~mm}$ phosphatidylserine at the indicated $\mathrm{pH}$. The reaction was started by the addition of recombinant protein, and $10 \mu \mathrm{l}$ aliquots were removed at different time points $(0.5-20 \mathrm{~min})$. The reaction was stopped by adding $15 \mu \mathrm{l}$ of $10 \mathrm{~mm} \mathrm{~N} N$-ethylmaleimide to the reaction mixture and incubating at $95^{\circ} \mathrm{C}$ for $10 \mathrm{~min}$, followed by centrifugation at $18000 \mathrm{~g}$ for $15 \mathrm{~min}$ at $4^{\circ} \mathrm{C}$. Phosphate release was measured with a malachite green-based assay as described before (31). The detection limit was 10 pmol released phosphate. Phosphatase assays with phosphorylated di-C6-NBD6 phosphatidylinositols (Echelon) were performed as described before (39) using $1 \mu \mathrm{g}$ lipid in $100 \mu \mathrm{l}$ assay buffer $(50 \mathrm{~mm}$ ammonium carbonate, $\mathrm{pH} 7.0,2$ mм DTT and $1 \mu \mathrm{g}$ enzyme). Phosphoinositides were separated on oxalate-coated $(1.2 \%$ potassium oxalate in methanol/water $2: 3, \mathrm{v} / \mathrm{v}$ ) silicagel $60 \mathrm{~W}$ plates (Merck), with chloroform/acetone/methanol/acetic acid/water $(80: 30: 26: 24: 14 \mathrm{v} / \mathrm{v})$ as mobile phase (40). For the PI3K/ Mtmr2 coupled assay, phosphoinositide substrates [phosphatidylinositol (Sigma), PI(4)P (Sigma) and PI(5)P, $5 \mu$ g each] were dissolved separately in chloroform/methanol $(2: 1 \mathrm{v} / \mathrm{v})$ and mixed with an equal amount of phosphatidylserine. The nitrogen-dried mixture was sonicated in $40 \mu \mathrm{l}$ of PI3K reaction buffer $\left(20 \mathrm{~mm}\right.$ HEPES at $\mathrm{pH} 7.4$ and $5 \mathrm{~mm} \mathrm{MgCl}_{2}$ ) and supplemented with $1 \mu \mathrm{g}$ of recombinant GST-PI3K $\gamma$ fusion protein (41) in $10 \mu \mathrm{l}$ reaction buffer. The phosphorylation reaction was started with $15 \mu \mathrm{Ci}$ of $\left[{ }^{32} \mathrm{P}\right] \gamma \mathrm{ATP}$ (from ICN) in $10 \mu 1$ reaction buffer to give a final concentration of $15 \mu \mathrm{M}$ ATP. After $20 \mathrm{~min}$ at $37^{\circ} \mathrm{C}$, the temperature was increased to $37^{\circ} \mathrm{C}$, and recombinant wild-type or catalytically inactive $\mathrm{Mtmr} 2$ protein $(1 \mu \mathrm{g} / \mathrm{sample})$ were added for $20 \mathrm{~min}$. Subsequently, lipids were extracted after the addition of $100 \mu \mathrm{l} 1 \mathrm{~m} \mathrm{HCl}$ and $200 \mu \mathrm{l}$ chloroform/methanol $(1: 1 \mathrm{v} / \mathrm{v})$ as described in (40). The lipids were separated as described above, and the radioactivity was quantified by phosphorimaging on a GS-525 from BioRad.

\section{In situ hybridization}

Brain, spinal cord, dorsal root ganglia and sciatic nerve from adult $\mathrm{C} 57 / \mathrm{B} 16$ mice were isolated and frozen in OTC (TissueTec) on dry ice. Twenty-micrometer frozen sections were mounted on Superfrost slides (Mettler) and air-dried. Digoxigenin-labeled RNA probes for in situ hybridization were produced with the full-length cDNA according to the manufacturer's recommendation (Roche Diagnostics, Mannheim). Hybridization was performed overnight at $72^{\circ} \mathrm{C}$ in buffer containing $50 \%$ formamide, and bound probe was detected using an anti-DIG-AP antibody (Roche Diagnostics, Mannheim). As a control, the in situ hybridization was repeated with a mouse Mtmr2 probe containing only the $3^{\prime}$-untranslated region. The same expression pattern as with the Mtmr2 cDNA full-length probe was found. Controls with the sense probes were always performed in parallel, with no appreciable signals detected.

\section{Immunocytochemistry}

A rabbit polyclonal antibody against Mtmr2 was raised using a recombinant Mtmr2 protein with an $\mathrm{N}$-terminal His tag. Dorsal root ganglia (DRG) were isolated from $\mathrm{C} 57 / \mathrm{B} 16$ mice at postnatal day 6 , dissociated by incubation in $0.35 \mathrm{mg} / \mathrm{ml}$ collagenase type $\mathrm{I} / 0.25 \%$ trypsin for $40 \mathrm{~min}$ at $37^{\circ} \mathrm{C}$, and plated on fibronectin-coated $35 \mathrm{~mm}$ cell culture dishes. The cells were cultivated in DMEM $/ 10 \%$ FCS for $36 \mathrm{~h}$ and then fixed in PBS containing $3.5 \%$ formaldehyde for $10 \mathrm{~min}$ at room temperature. The cells were then permeabilized for $10 \mathrm{~min}$ at room temperature in $0.2 \%$ Triton X-100/ $5 \%$ normal goat serum (NGS) in PBS. Mtmr2 labeling was performed using a rabbit polyclonal antibody diluted $1: 1000$ in $0.2 \%$ Triton X-100/ 5\% NGS/PBS. Mouse monoclonal anti-Sox10 antibody (kindly provided by Dr M. Wegner, University of Erlangen, Germany) was used in a $1: 3$ dilution. Detection was carried out with either Cy3-conjugated goat anti-rabbit (Jackson ImmunoResearch Laboratories, 1:500) or FITC-conjugated goat antimouse IgGs (Sigma, 1:300).

\section{ACKNOWLEDGEMENTS}

We thank Drs Ned Mantei, Lukas Sommer and Verdon Taylor for many helpful discussions and critical reading of the manuscript, Dr Michael Wegner for antibodies, and G. Bulgarelli-Leva for excellent technical assistance. This work was supported by the Swiss National Science Foundation, the Swiss Muscle Disease Foundation, the Wolfermann-Nägeli Stiftung, the National Center of Competence in Research 'Neural Plasticity and Repair', and the Swiss Bundesamt for Science related to the Commission of the European Communities, specific RTD programme 'Quality of Life and Management of Living Ressources', QLK6-CT-2000-00179.

\section{REFERENCES}

1. Quattrone, A., Gambardella, A., Bono, F., Aguglia, U., Bolino, A., Bruni, A.C., Montesi, M.P., Oliveri, R.L., Sabatelli, M., Tamburrini, O. et al. (1996) Autosomal recessive hereditary motor and sensory neuropathy with focally folded myelin sheaths: clinical, electrophysiologic, and genetic aspects of a large family. Neurology, 46, 1318-1324.

2. Gambardella, A., Bolino, A., Muglia, M., Valentino, P., Bono, F., Oliveri, R.L., Sabatelli, M., Brancolini, V., Van Broeckhoven, C., Romeo, G. et al. (1998) Genetic heterogeneity in autosomal recessive hereditary motor and sensory neuropathy with focally folded myelin sheaths (CMT4B). Neurology, 50, 799-801.

3. Bolino, A., Levy, E.R., Muglia, M., Conforti, F.L., LeGuern, E., Salih, M.A., Georgiou, D.M., Christodoulou, R.K., Hausmanowa-Petrusewicz, I., Mandich, P. et al. (2000) Genetic refinement and physical mapping of the CMT4B gene on chromosome 11q22. Genomics, 63, 271-278.

4. Bolino, A., Muglia, M., Conforti, F.L., LeGuern, E., Salih, M.A., Georgiou, D.M., Christodoulou, K., Hausmanowa-Petrusewicz, I., Mandich, P., Schenone, A. et al. (2000) Charcot-Marie-Tooth type 4B is caused 
by mutations in the gene encoding myotubularin-related protein-2. Nat. Genet., 25, 17-19.

5. Houlden, H., King, R.H., Wood, N.W., Thomas, P.K. and Reilly, M.M (2001) Mutations in the $5^{\prime}$ region of the myotubularin-related protein 2 (MTMR2) gene in autosomal recessive hereditary neuropathy with focally folded myelin. Brain, 124, 907-915.

6. Laporte, J., Blondeau, F., Buj-Bello, A., Tentler, D., Kretz, C., Dahl, N., and Mandel, J.L. (1998) Characterization of the myotubularin dual specificity phosphatase gene family from yeast to human. Hum. Mol. Genet., 7, $1703-1712$.

7. Laporte, J., Hu, L.J., Kretz, C., Mandel, J.L., Kioschis, P., Coy, J.F., Klauck, S.M., Poustka, A. and Dahl, N. (1996) A gene mutated in X-linked myotubular myopathy defines a new putative tyrosine phosphatase family conserved in yeast. Nat. Genet., 13, 175-182.

8. Sarnat, H.B. (1990) Myotubular myopathy: arrest of morphogenesis of myofibres associated with persistence of fetal vimentin and desmin. Four cases compared with fetal and neonatal muscle. Can. J. Neurol. Sci., 17, $109-123$.

9. Laporte, J., Blondeau, F., Buj-Bello, A. and Mandel, J.L. (2001) The myotubularin family: from genetic disease to phosphoinositide metabolism. Trends Genet., 17, 221-228.

10. Wishart, M.J., Taylor, G.S., Slama, J.T. and Dixon, J.E. (2001) PTEN and myotubularin phosphoinositide phosphatases: bringing bioinformatics to the lab bench. Curr. Opin. Cell Biol., 13, 172-181.

11. Taylor, G.S., Maehama, T. and Dixon, J.E. (2000) Inaugural article: myotubularin, a protein tyrosine phosphatase mutated in myotubular myopathy, dephosphorylates the lipid second messenger, phosphatidylinositol 3-phosphate. Proc. Natl Acad. Sci. USA, 97, 8910-8915.

12. Maehama, T. and Dixon, J.E. (1998) The tumor suppressor, PTEN/ MMAC1, dephosphorylates the lipid second messenger, phosphatidylinositol 3,4,5-trisphosphate. J. Biol. Chem., 273, 13375-13378.

13. Schu, P.V., Takegawa, K., Fry, M.J., Stack, J.H., Waterfield, M.D. and Emr, S.D. (1993) Phosphatidylinositol 3-kinase encoded by yeast VPS34 gene essential for protein sorting. Science, 260, 88-91.

14. Brown, W.J., DeWald, D.B., Emr, S.D., Plutner, H. and Balch, W.E. (1995) Role for phosphatidylinositol 3-kinase in the sorting and transport of newly synthesized lysosomal enzymes in mammalian cells. J. Cell. Biol., 130, 781-796.

15. Martin, T.F. (1998) Phosphoinositide lipids as signaling molecules: common themes for signal transduction, cytoskeletal regulation, and membrane trafficking. Annu. Rev. Cell Dev. Biol., 14, 231-264.

16. Vanhaesebroeck, B., Leevers, S.J., Panayotou, G. and Waterfield, M.D. (1997) Phosphoinositide 3-kinases: a conserved family of signal transducers. Trends Biochem. Sci., 22, 267-272.

17. Corvera, S., D'Arrigo, A. and Stenmark, H. (1999) Phosphoinositides in membrane traffic. Curr. Opin. Cell Biol., 11, 460-465.

18. Odorizzi, G., Babst, M. and Emr, S.D. (2000) Phosphoinositide signaling and the regulation of membrane trafficking in yeast. Trends Biochem. Sci., 25, 229-235.

19. Gaullier, J.M., Simonsen, A., D'Arrigo, A., Bremnes, B., Stenmark, H. and Aasland, R. (1998) FYVE fingers bind PtdIns(3)P. Nature, 394, 432-433.

20. Gillooly, D.J., Morrow, I.C., Lindsay, M., Gould, R., Bryant, N.J., Gaullier, J.M., Parton, R.G. and Stenmark, H. (2000) Localization of phosphatidylinositol 3-phosphate in yeast and mammalian cells. EMBO J., 19, 4577-4588.

21. Shisheva, A., Rusin, B., Ikonomov, O.C., DeMarco, C. and Sbrissa, D. (2001) Localization and insulin-regulated relocation of phosphoinositide 5-kinase PIKfyve in 3T3-L1 adipocytes. J. Biol. Chem., 276, 11859-11869.

22. Dove, S.K., Cooke, F.T., Douglas, M.R., Sayers, L.G., Parker, P.J. and Michell, R.H. (1997) Osmotic stress activates phosphatidylinositol-3,5bisphosphate synthesis. Nature, 390, 187-192.
23. Gary, J.D., Wurmser, A.E., Bonangelino, C.J., Weisman, L.S. and Emr, S.D. (1998) Fab1p is essential for PtdIns(3)P 5-kinase activity and the maintenance of vacuolar size and membrane homeostasis. J. Cell. Biol., 143, 65-79.

24. Odorizzi, G., Babst, M. and Emr, S.D. (1998) Fab1p PtdIns(3)P 5-kinase function essential for protein sorting in the multivesicular body. Cell, 95, $847-858$.

25. Berger, P., Young, P. and Suter, U. (2002) Molecular cell biology of Charcot-Marie-Tooth disease. Neurogenetics, 4, 1-15.

26. Doerks, T., Strauss, M., Brendel, M. and Bork, P. (2000) GRAM, a novel domain in glucosyltransferases, myotubularins and other putative membrane-associated proteins. Trends Biochem. Sci., 25, 483-485.

27. Cui, X., De Vivo, I., Slany, R., Miyamoto, A., Firestein, R. and Cleary, M.L. (1998) Association of SET domain and myotubularin-related proteins modulates growth control. Nat. Genet., 18, 331-337.

28. Kioschis, P., Wiemann, S., Heiss, N.S., Francis, F., Gotz, C., Poustka, A., Taudien, S., Platzer, M., Wiehe, T., Beckmann, G. et al. (1998) Genomic organization of a $225-\mathrm{kb}$ region in Xq28 containing the gene for X-linked myotubular myopathy (MTM1) and a related gene (MTMR1). Genomics, 54, 256-266.

29. Blondeau, F., Laporte, J., Bodin, S., Superti-Furga, G., Payrastre, B. and Mandel, J.L. (2000) Myotubularin, a phosphatase deficient in myotubular myopathy, acts on phosphatidylinositol 3-kinase and phosphatidylinositol 3-phosphate pathway. Hum. Mol. Genet., 9, 2223-2229.

30. Walker, D.M., Urbe, S., Dove, S.K., Tenza, D., Raposo, G. and Clague, M.J. (2001) Characterization of MTMR3. an inositol lipid 3-phosphatase with novel substrate specificity. Curr. Biol., 11, 1600-1605.

31. Maehama, T., Taylor, G.S., Slama, J.T. and Dixon, J.E. (2000) A sensitive assay for phosphoinositide phosphatases. Anal. Biochem., 279, 248-250.

32. Paratore, C., Goerich, D.E., Suter, U., Wegner, M. and Sommer, L. (2001) Survival and glial fate acquisition of neural crest cells are regulated by an interplay between the transcription factor Sox 10 and extrinsic combinatorial signaling. Development, 128, 3949-3961.

33. Kim, S.A., Taylor, G.S., Torgersen, K.M. and Dixon, J.E. (2002) Myotubularin and MTMR2, Phosphatidylinositol 3-phosphatases mutated in myotubular myopathy and type 4B Charcot-Marie-Tooth disease. $J$. Biol. Chem., 277, 4526-4531.

34. Jones, D.R., Gonzalez-Garcia, A., Diez, E., Martinez, A.C., Carrera, A.C and Merida, I. (1999) The identification of phosphatidylinositol 3,5bisphosphate in T-lymphocytes and its regulation by interleukin-2. J. Biol. Chem., 274, 18407-18413.

35. Ikonomov, O.C., Sbrissa, D. and Shisheva, A. (2001) Mammalian cell morphology and endocytic membrane homeostasis require enzymatically active phosphoinositide 5-kinase PIKfyve. J. Biol. Chem., 276, 2614126147.

36. Meijer, H.J., Berrie, C.P., Iurisci, C., Divecha, N., Musgrave, A. and Munnik, T. (2001) Identification of a new polyphosphoinositide in plants, phosphatidylinositol 5-monophosphate (PtdIns5P), and its accumulation upon osmotic stress. Biochem. J., 360, 491-498.

37. Zhao, R., Qi, Y. and Zhao, Z.J. (2000) FYVE-DSP1, a dual-specificity protein phosphatase containing an FYVE domain. Biochem. Biophys. Res. Commun., 270, 222-229.

38. Laporte, J., Liaubet, L., Blondeau, F., Tronchere, H., Mandel, J.L. and Payrastre, B. (2002) Functional redundancy in the myotubularin family. Biochem. Biophys. Res. Commun., 291, 305-312.

39. Taylor, G.S. and Dixon, J.E. (2001) An assay for phosphoinositide phosphatases utilizing fluorescent substrates. Anal. Biochem., 295, 122-126.

40. Arcaro, A. and Wymann, M.P. (1993) Wortmannin is a potent phosphatidylinositol 3-kinase inhibitor: the role of phosphatidylinositol 3,4,5trisphosphate in neutrophil responses. Biochem. J., 296, 297-301.

41. Bondeva, T., Pirola, L., Bulgarelli-Leva, G., Rubio, I., Wetzker, R. and Wymann, M.P. (1998) Bifurcation of lipid and protein kinase signals of PI3Kgamma to the protein kinases PKB and MAPK. Science, 282, 293-296. 